\title{
Orbital lymphoma in a patient with Felty's syndrome
}

\author{
Paul S Nassif, Steven E Feldon
}

\begin{abstract}
A 72-year-old woman presented with a diffuse infiltrating soft tissue mass involving the entire right orbit. She had a pre-existing phthisis of the right eye secondary to retinal detachment, and had developed painless proptosis on the same side. Her medical history included rheumatoid arthritis, leucopenia, and an enlarged spleen, characteristics consistent with the diagnosis of Felty's syndrome. Risk of lymphoma is thought to be higher in patients with established connective tissue disorders. The case described herein, to our knowledge, represents the first report of an association between Felty's syndrome and orbital lymphoma. The symptoms of Felty's syndrome in our patient were initially attributed to spread of a malignant process involving the orbit.
\end{abstract}

\section{Case report}

A 72-year-old woman with pre-existing phthisis of the right eye secondary to retinal detachment developed painless proptosis on the same side. The proptosis was unresponsive to antibiotics or anti-inflammatory agents. Vision in the right eye was no light perception and a $4+$ afferent pupillary defect was present. We obtained exophthalmometry readings of $29 \mathrm{~mm}$ on the right and $17 \mathrm{~mm}$ on the left, with a base of $110 \mathrm{~mm}$. The left eye was normal. Magnetic resonance imaging (MRI) and computed tomography (CT) revealed a diffuse infiltrating soft tissue mass involving the entire right orbit. No bony changes were present and the sinuses were clear (Fig 1).

Systemic work-up demonstrated hepatosplenomegaly, a white blood cell count of $1 \cdot 8 \times 10^{9} / 1$, haematocrit of $37 \cdot 1 \%$, and platelet count of $96 \times 10^{9} / 1$ with giant forms present.

Serum antinuclear antibody (ANA) titre was positive at $1: 80$, rheumatoid factor was negative, and the angiotensin-converting enzyme level was normal. The sedimentation rate was $20 \mathrm{~mm} / \mathrm{h}$ (Westergren). Tests for anti-DNA double strand antibody, anti-scleroderma antibody, and antibodies associated with Sjögren's syndrome were negative. We interpreted these findings as consistent with metastatic carcinoma or with disseminated lymphoma.

The physical examination prompted us to study further the patient's medical history. She then volunteered a history of rheumatoid arthritis, leucopenia, and an enlarged spleen. Medical records from 9 years prior to presentation showed strongly positive rheumatoid factor and a positive ANA titre. A white blood cell count of $1.4 \times 10^{9} / 1$, a platelet count of $181 \times 10^{9} / 1$, and a broad-based polyclonal gammopathy were found. A bone marrow aspiration demonstrated myeloid and erythroid hyperplasia. Based upon these findings the patient had been diagnosed as having Felty's syndrome.

The orbital mass biopsy and subsequent workup were diagnostic for a stage Ia large cleaved cell lymphoma of the B type, localised to the orbit (Fig 2). A 5 week course of 5000 cGy of local radiation therapy to the right orbit produced complete regression of the tumour by radioimaging studies.

\section{Discussion}

In 1924 Felty $^{1}$ reported five adults with chronic rheumatoid arthritis (RA) who had associated splenomegaly, leucopenia, and hypochromic anaemia, with or without a reduced platelet count. This syndrome occurs in less than $1 \%$ of patients with RA and is twice as common in women as in men. ${ }^{2}$

Patients with long-standing connective tissue

\section{Accepted for publication 8 August 1991 \\ Departments of University of Souther Medicine, and the Los Angeles, California, P S Nassif \\ Correspondence to: Steven E Feldon, MD,
Doheny Eye Institute, 1355 Doheny Eye Institute, 1355}
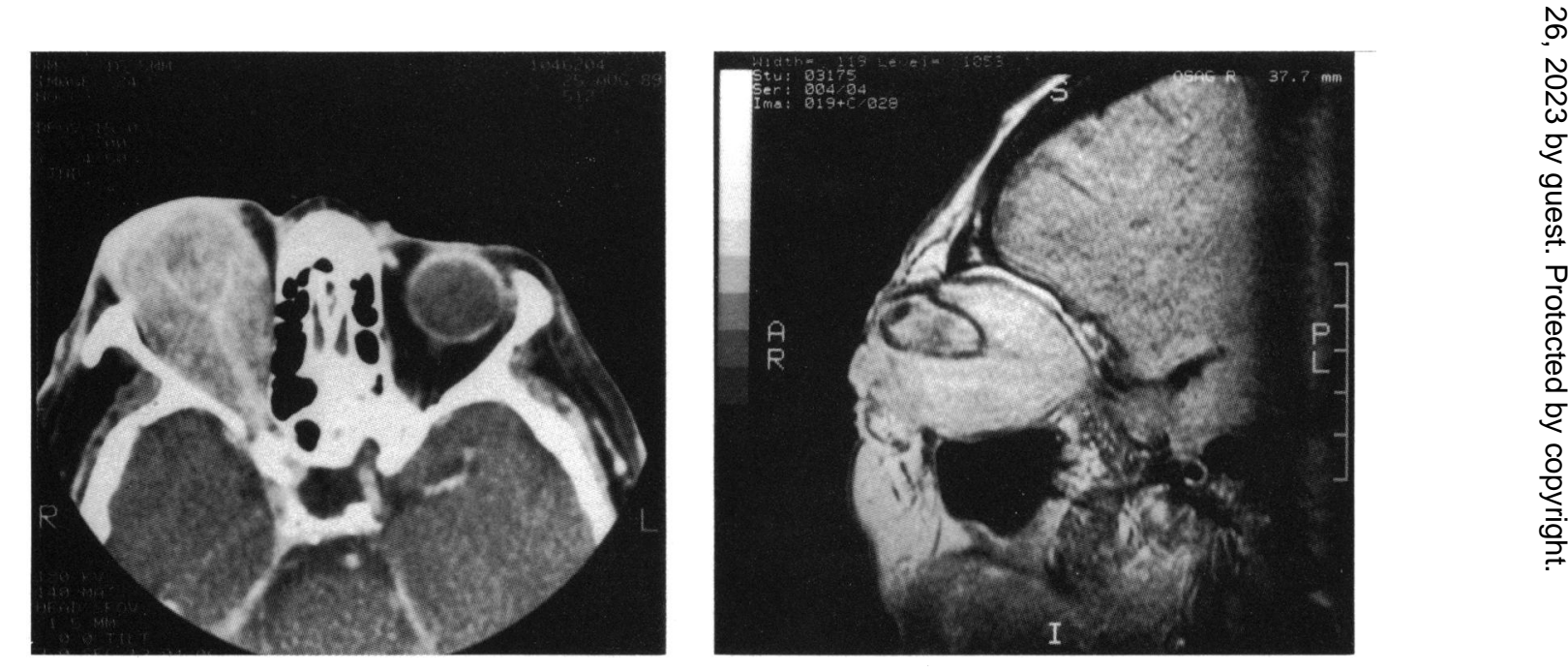

Figure 1 Diffuse infiltration of the right orbit, proptosis, and shrunken globe are demonstrated by axial CT scan (left) and by sagittal MRI (right). 


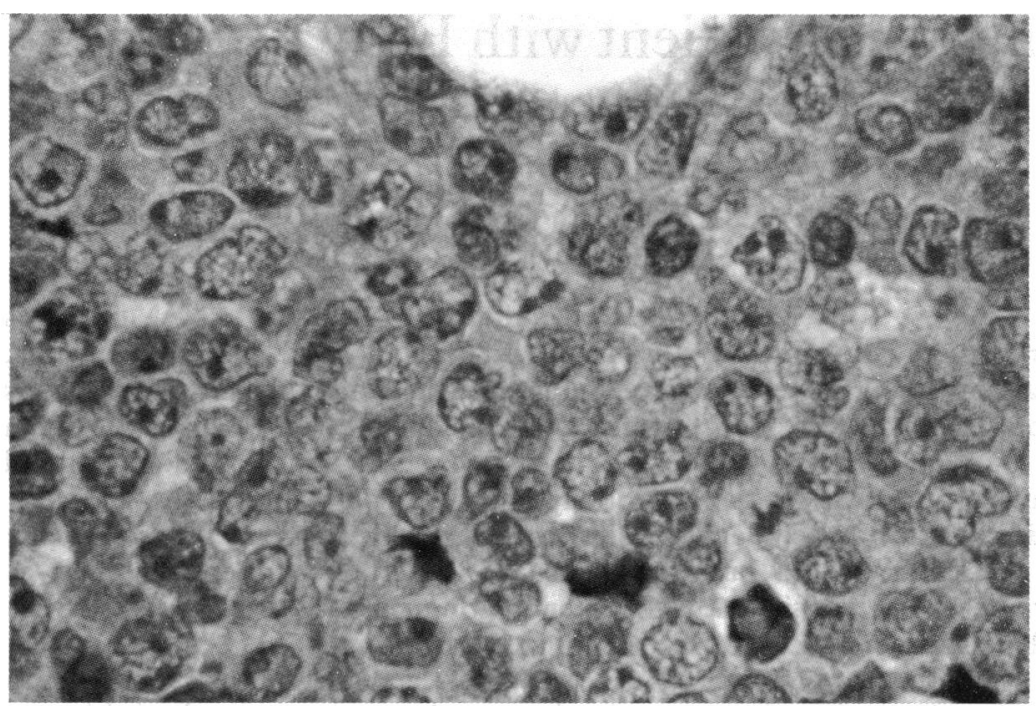

Figure 2 Photomicrograph of the orbital biopsy $(\times 690)$ showing a large cleaved cell lymphoma of the B type. Clumping of nuclear material is prominent and occasional mitoses are seen. The white rounded spot at the top of the figure represents a fat globule.

disorders are thought to be at higher risk of developing lymphoma than is the general population. ${ }^{3}$ For instance, patients with Sjögren's syndrome are about 44 times more likely to develop lymphoma than is the general population. ${ }^{4}$ However the lymphomas associated with Sjögren's syndrome have been of the diffuse histiocytic type ${ }^{5}$ rather than of the large cleaved cell variety found in our patient; furthermore antigen associated with Sjögren's syndrome was absent in our patient.

The development of lymphoma in the setting of long-standing connective tissue disease may be explained either by chronic immunostimulation leading to lymphoid hyperplasia and, eventually, to malignancy, ${ }^{6}$ or by a disturbance in immune surveillance.

As orbital lymphoma associated with Felty's syndrome has not been previously reported, ophthalmologists should be alert to this diagnosis when evaluating patients with suggestive findings. In particular, the hepatosplenomegaly, neutropenia, and thrombocytopenia which often indicate diffuse spread of a malignancy may occasionally signify an underlying benign inflammatory process in association with localised lymphoma.

1 Felty AR. Chronic arthritis in the adult, associated with splenomegaly and leucopenia: a report of five cases of an unusual clinical syndrome. Fohns Hopkins Hosp Bull 1924; 35: $16-20$

2 Isomaki $\mathbf{H}$, Koivisto $\mathrm{O}$, Kiviniitty $\mathrm{K}$. Splenomegaly in rheumatoid arthritis. Acta Rheumatol Scand 1971; 17: 23-6.

3 Hench PK, Mayne JG, Kiely JM, Dockerty MB. Clinical study of the rheumatic manifestations of lymphoma. Arthritis Rheum 1962; 5: 301 .

4 Talal N, Schnitzer B. Lymphadenopathy and Sjögren's syndrome. Clin Rheum Dis 1977; 3: 421-32.

5 Kassan SS, Thomas TL, Moutsopoulos HM, et al. Increased risk of lymphoma in sicca syndrome. Ann Intern Med 1978, 89: 888-92.

6 Mills JA. A spectrum of organ systems that respond to cancer: the joints and connective tissue. Ann NY Acad Sci 1974; 230: 443-7. 